\title{
Gas antisolvent fractionation based optical resolution of ibuprofen with enantiopure phenylglycinol
}

\author{
L. Lőrincz ${ }^{1}$, Á. Tóth ${ }^{1}$, L. Kondor ${ }^{1}$, O. Kéri ${ }^{2}$, J. Madarász $^{2}$, E. Varga $^{3}$, E. Székely ${ }^{1 *}$ \\ ${ }^{1}$ Budapest University of Technology and Economics; Department of Chemical and \\ Environmental Process Engineering; Müegyetem rkp 3., Budapest, Hungary, H-1111 \\ ${ }^{2}$ Budapest University of Technology and Economics, Department of Inorganic and Analytical \\ Chemistry; Mủegyetem rkp 3., Budapest, Hungary, H-1111 \\ ${ }^{3}$ Cyclolab Ltd.; Illatos út 7., Budapest, Hungary, H-1097
}

\begin{abstract}
Optical resolution is still the dominant route to obtaining enantiopure active ingredients. The traditional methods require large organic solvent quantities and long processing times. Antisolvent fractionation with supercritical carbon dioxide offers intensified processing by drastically reducing the time requirement of the diastereomeric salt precipitation. A novel optical resolution of ibuprofen was developed and optimized with phenylglycinol as a resolving agent and gas antisolvent fractionation as the separation method. Above the critical values of certain operational parameters (carbon dioxide to methanol ratio, apparent diastereomeric salt concentration, equilibration time, the relative volume of the extracting fluid) the selectivity was roughly constant, the optical resolution is robust. The scalemic mixtures were purified by repeated resolution and enantiomeric purities above $99 \%$ were reached in three consecutive steps.
\end{abstract}

\section{Keywords}

crystallization, supercritical carbon dioxide, process intensification, gas antisolvent process, scalemic mixture, enantiomer

\section{Highlights}

Efficient optical resolution of ibuprofen by gas antisolvent fractionation.

Phenylglycinol is an excellent resolving agent of ibuprofen

Purification of scalemic mixtures by repeated resolution to $>99 \%$ in 3 steps

Thin fibers with diameters in the nanometer range $(400-800 \mathrm{~nm})$ were produced. 


\section{Introduction}

There is a growing demand for technologies with low environmental impact in several areas of the chemical industry [1]. There is an urgent need, especially in the pharmaceutical industry, for innovative and productive processes in contrast with traditional batch processes [2]. Supercritical carbon dioxide [3] based methods are good candidates for replacing slower, organic solvent consuming technologies. Carbon dioxide is a non-expensive, non-toxic, ecofriendly nonpolar solvent, which can be recovered and reused by condensation and compression. One of the major advantages from the viewpoint of the pharmaceutical industry, besides the possibility of continuous precipitation, is that after depressurization a solvent free solid crystalline or amorphous powder is typically obtained. The solubility, supersaturation and diffusion controlled phenomena can be fine-tuned by pressure and temperature.

Various supercritical carbon dioxide technologies have been developed over the past decades, and many of them are applied at industrial scales. Extraction of biologically active or edible component from plants [4] is the most widely applied supercritical carbon dioxide process, but its reverse process, the impregnation of wood [5][6] or polymers [7] and textile dying has also been upscaled. The enhanced diffusion coefficients of supercritical fluids are especially useful for drug formulations [8] and chemical [9] or enzyme [10] catalyzed reactions. The first study on using supercritical fluid extraction for optical resolution was published in the mid 90’s by Simándi and Fogassy [11].

Optical resolution is a process in which enantiomers are separated from their one-to-one mixture, referred to as racemate. Separating enantiomers became the focus of attention in the 1960's when the Contergan scandal highlighted that different enantiomers of pharmaceutical ingredients can have different, sometimes dangerous effects. Nowadays chiral drugs can be only marketed in their enantiopure forms unless a one-to-one mixture of the enantiomers, has the same efficiency. Racemates are obtained by non-chiral synthesis, and the isolation of single enantiomers is required as they typically have different biological effects and activities. Since the first publication of Simándi and his group, several supercritical extraction based optical resolutions have been investigated [12][13][14]. The in situ process [15] employs carbon dioxide as the only solvent to produce optically active salts, while a two-step carbon dioxide extraction process subsequent to the melt crystallization of the diastereomers [13] is also possible.

Small, relatively non-polar molecules typically dissolve readily in supercritical carbondioxide. When processing an active pharmaceutical ingredient that has a larger molecular 
weight or a more polar character [16], it is recommended to use supercritical antisolvent technologies. With these antisolvent methods, heat-sensitive substances can be micronized to obtain large specific surface areas and thus increased dissolution rates. Antisolvent technologies, especially antisolvent precipitation, were first mentioned in connection with micronizing explosives [17], later the techniques were applied for inorganic salts [18] and active pharmaceutical ingredients [19]. Changes in crystal structures and morphological variations [20][21][22][23] caused by varying the process parameters were extensively studied. Multiple review articles are available in the antisolvent precipitation field $[24][25][26][27]$.

When gas antisolvent precipitation is combined with an extraction, it is referred to as supercritical antisolvent extraction [28], or supercritical antisolvent fractionation [29]. We prefer to use the latter term.

So far, antisolvent techniques have been used for optical resolutions only in a few cases $[30][31][32][33][34][35][36][37]$ and even less so for the enrichment of scalemic mixtures (i.e. nonracemic enantiomeric mixture, a mixture having non-zero enantiomeric excess value) [34][35].

This study presents a novel optical resolution of ibuprofen (IBU) with optically active $(S)$-2phenylglycinol (PhG).

Ibuprofen is a non-steroidal analgesic and a widely used pharmaceutical model compound used for research purposes. Ibuprofen's $(S)$ enantiomer is approximately 3 times more effective than its racemic form [38]. Optical resolution of ibuprofen has already been demonstrated with multiple technologies, such as crystallization from organic solution [39], making it a good basis of comparison when developing a resolution system. The resolution of ibuprofen was investigated and recommended with several different resolving agents, for example ephedrine [39], phenylethylamine [40] or lysine [41]. Resolution of ibuprofen with $(S)$-phenylglycinol was previously investigated by the in situ method, without any success [42]. However, structural similarities [43] and differential scanning calorimetry (DSC) analysis results [44] suggest that $(S)$-phenylglycinol could be a suitable resolving agent. The efficiency of an optical resolution in general is strongly influenced by the properties of the solvent and the conditions under which the solid phase is formed. Taking the DSC results and the typical sensitivity of optical resolutions into account, we were motivated to develop a suitable optical resolution method for ibuprofen with phenylglycinol, applying an antisolvent approach. 


\section{Materials and Methods}

\subsection{Materials}

Racemic ibuprofen (2-(4-isobutylphenyl)propanoic acid) ( $\geq 98 \%$ ), $(S)$-ibuprofen ( $\geq 98 \%$ ) and (S)-2-phenylglycinol ( $\geq 97 \%$ ) were purchased from Tokyo Chemical Industry Ltd. Carbon dioxide ( $\geq 99.5 \%$ ) was purchased from Linde Gas Hungary Co. Cltd and was used freshly distilled. Methanol ( $\geq 99.5 \%)$ was purchased from Merck Ltd.

\subsection{Gas antisolvent fractionation procedure}

The optical resolution was performed by the half-molar-equivalent method (Fig 1.). According to the DSC thermograms, $(S)$-PhG forms a more stable salt with $(S)$-IBU than with $(R)$-IBU [44], because the homochiral $(S-S, R-R)$ interactions are stronger than the interactions in the racemate type crystals [45]. The raffinate is enriched in $(S)-\mathrm{IBU}-(S)-\mathrm{PhG}$, the more stable diastereomeric salt, while the fluid phase is enriched in $(R)$-IBU.

For each experiment, solid ibuprofen (0.075-0.35 g, typically $0.15 \mathrm{~g})$ and $(S)$-phenylglycinol (0.025-0.1167 g, typically $0.05 \mathrm{~g}$ ) were dissolved in a calculated volume of methanol, 0.3-4.5 $\mathrm{ml}$, typically $2 \mathrm{ml}$. The solution was left for 5-10 minutes to ensure that the powder is completely dissolved, then pipetted into the preheated reactor. In certain experiments, the initial enantiomeric purity of the scalemic ibuprofen mixture (i.e. ibuprofen with $>0$ enantiomeric excess) was set by adding calculated amounts of $(S)$-ibuprofen to the racemate. A detailed description of the reactors can be found in our earlier paper [36]. The reactors were constructed by the Applied Chemistry Research Institute of Miskolc University and an inlet tube was built in to increase washing efficiency. The reactors are suitable for operation with carbon dioxide up to $25 \mathrm{MPa}$ and $100^{\circ} \mathrm{C}$. The reactors are equipped with a rupture disc opening at $34 \mathrm{MPa}$. Three reactors were used in this study with slightly different volumes ranging from 36.4 to $37.7 \mathrm{ml}$.

After pipetting in the liquid solution of ibuprofen and the resolving agent, the reactor was sealed, then stirred at $750 \mathrm{rpm}$ while pressurized with carbon dioxide to the desired pressure, typically within 10-15 minutes. The reaction mixture was stirred at constant pressure and temperature for a predetermined time $(t)$, followed by extraction of the dissolved components with carbon dioxide. This latter step, called washing, lasted 40 to 80 minutes depending on the amount of the $\mathrm{CO}_{2}$ used. The amount of carbon dioxide used for washing was calculated from the volume change of the ISCO 260D piston pump which was maintained at a known pressure and temperature.

The extract was trapped in $40 \mathrm{ml}$ methanol, then vacuum distilled and weighed. After depressurization of the reactor, the majority of the raffinate was recovered in solid form, the 
rest was washed out with methanol in order to improve the material balance. During the washing phase, any material after the metal filter was regarded as extract, while material before the filter was regarded as raffinate.

The simplified reaction scheme is shown in Fig 1. Obviously, the enantiomeric and diastereomeric purities of the unreacted ibuprofen and the diastereomeric salt, respectively, are not $100 \%$. Since the fluid phase is enriched in $(R)$-IBU, the extract will contain more $(R)$ IBU enantiomer than $(S)$-IBU.<smiles>CC(C)Cc1ccc([C@@H](C)C(=O)O)cc1</smiles>

(S)-IBU<smiles>N[C@H](CO)c1ccccc1</smiles>

(S)-PhG<smiles>CC(C)Cc1ccc([C@@H](C)C(=O)O)cc1</smiles>

$(R)-\mathrm{IBU}$<smiles>[CH2]C(=O)[C@H](C)c1ccc(CC(C)C)cc1</smiles><smiles>CCCCCCCCCCC(C)CC(C)CC(C)C</smiles>

Fig. 1. Reaction scheme of the optical resolution of ibuprofen with (S)-phenylglycinol.

\subsection{Analysis}

A description of the capillary electrophoresis, powder X-ray diffraction (XRD) and scanning electron microscopy (SEM) methods were published in our previous work [36].

The diastereomeric purity of the raffinate (also known as diastereomeric excess, de, indicating the share of the excess diastereomer) can be calculated from the peak areas of the electropherograms $\left(A_{R}, A_{S}\right)$. Because the diastereomeric salt is dissolved prior to electrophoresis, the analysis effectively measures enantiomer quantities. The formula of the enantiomeric purity (enantiomeric excess, ee) according to eq. 1.:

$\mathrm{de}=\mathrm{ee}_{S, \mathrm{IBU}}=\frac{A_{S}-A_{R}}{A_{S}+A_{R}}($ eq. 1.$)$ 


\subsection{Calculations}

The molar ratio of carbon dioxide and methanol $(R)$ was calculated with the following formula:

$R=n_{\mathrm{CO}_{2}} / n_{\mathrm{MeOH}}$ ( eq. 2.)

In the above equation (eq. 2.), $n_{\mathrm{CO}_{2}}$ denotes the molar amount (mol) of carbon dioxide in the reactor that was calculated from the volume change of the syringe pump during pressurization of the reactor [36], while $n_{\mathrm{MeOH}}$ denotes the molar amount (mol) of methanol.

The raffinate yields $\left(Y_{r}\right)$ were calculated relative to the theoretical mass of the raffinate (eq. 3.).

$Y_{r}=m_{r} / m_{r \text {,h }}$ (eq. 3.)

The theoretical mass of the raffinate $\left(m_{r, \text { th }}\right)$ is the calculated mass of diastereomers, i.e. the mass of diastereomeric salt equal in number of moles (mr) to the resolving agent (eq. 4.) according to the idealized reaction scheme presented in Fig. 1. at full conversion.

$m_{r, \text { th }}=\mathrm{mr} \cdot m_{\mathrm{IBU}}+m_{\mathrm{PhG}}$ (eq. 4.)

According to the current and previous results, this assumption is correct [46].

The apparent concentration of the diastereomeric salt $(C)$ was calculated for the total volume of the reactor with eq. 5., where $V$ denotes the used reactor volume (ml).

$C=m_{r, \text { th }} / V$ (eq. 5.)

Selectivity $\left(S_{r}\right)$ is the most important term describing the efficiency of an optical resolution process, first suggested by Fogassy et al. [47]. This term combines yields and purities, since an optical resolution demands both high yields and purities. Selectivity allows optimization of an optical resolution, where higher yields are typically paired with lower purities and vice versa. Selectivity values are in the range of $0-1$.

Raffinate selectivity was calculated with the following formula (eq. 6.):

$S_{r}=Y_{r} \cdot$ de ( eq. 6.)

The relative volume of the extracting fluid $(\triangle V / V)$ was calculated with the following formula (eq. 7.):

$\frac{\Delta V}{V}=\frac{V_{\mathrm{CO}_{2}} \cdot \frac{\rho_{\text {isco }}}{\rho_{\text {reactor }}}}{V}($ eq. 7.)

In this formula (eq. 7.), $V_{\mathrm{CO}_{2}}$ denotes the total volume of carbon dioxide used for the extraction, calculated from volume change of the ISCO syringe pump, $\rho_{\text {isco }}$ denotes the density of carbon dioxide in the ISCO syringe pump $\left(24^{\circ} \mathrm{C}\right.$ and reactor pressure $), \rho_{\text {reactor }}$ denotes the density of carbon dioxide at the conditions in the reactor. Densities were looked up from www.webbook.nist.gov. 


\section{Results and discussion}

Preliminary experiments on the antisolvent based optical resolution of ibuprofen with $(S)$ phenylglycinol resulted in white crystalline precipitate as raffinate with de values higher than $50 \%$. Following the proof of principle optical resolution we performed a detailed investigation of the parameter-sensitivity of the optical resolution system and the purification of the scalemic mixtures as well.

\subsection{Effect of the extraction step}

Although extraction is the last phase of the complete optical resolution, its efficiency and standardization is crucial for the evaluation of the reaction parameters. The effects of $\Delta V / V$ are shown in Table 1. In each case, the products were dry, solvent-free crystals when the value of $\Delta V / V$ was at least two, while at lower values, wet raffinates were obtained. Since the aim of extraction is to remove the methanol and unreacted enantiomers, this result is in agreement with our expectations based on residence time distribution based extraction efficiency calculations of a continuous stirred tank reactor (CSTR) [15].

\begin{tabular}{|l|l|l|l|}
\hline$\Delta V / V$ & $d e$ & $Y_{r}$ & $S_{r}$ \\
\hline $\mathbf{2 . 0}$ & 0.60 & 0.69 & 0.41 \\
\hline $\mathbf{2 . 0}$ & 0.53 & 0.72 & 0.38 \\
\hline $\mathbf{2 . 0}$ & 0.6 & 0.80 & 0.48 \\
\hline $\mathbf{2 . 9}$ & 0.68 & 0.64 & 0.43 \\
\hline $\mathbf{4 . 0}$ & 0.64 & 0.63 & 0.41 \\
\hline
\end{tabular}

Table 1. Effects of the extraction on the values of diastereomeric excess, yield and selectivity. $\left(P=15 \mathrm{MPa} ; \mathrm{T}=42.5^{\circ} \mathrm{C} ; \mathrm{R}=12 ; \mathrm{t}=1 \mathrm{~h} ; \mathrm{C}=3.5 \mathrm{mg} / \mathrm{ml}\right)$

$\triangle V / V$ does not have any significant effect on the diastereomeric purity or the yield, therefore it does not influence the raffinate selectivity in the studied range. Thus, it is recommended to perform the extraction with twice as much fluid as the volume of the reactor, in order to reduce carbon dioxide usage and operational time.

\subsection{Equilibration time}

Gas antisolvent precipitation is known to be instantaneous due to the significant oversaturation caused by the addition of the carbon dioxide. We have not found any studies among gas antisolvent extraction or fractionation investigations which evaluated the time required to stabilize the composition and amount of the precipitate. This time might be influenced by the oversaturation rate, crystal growth rate and kinetic effects. The equilibration 
time is the time elapsed between filling the reactor to a given pressure and the beginning of the extraction. At $t=0$, the extraction (washing with carbon dioxide) started immediately after the reactor was completely filled. The results are summarized in Table 2.

\begin{tabular}{|c|l|l|l|}
\hline$t[h]$ & $d e$ & $Y_{r}$ & $S_{r}$ \\
\hline $\mathbf{0}$ & 0.15 & 0.88 & 0.13 \\
\hline $\mathbf{0 . 5}$ & 0.59 & 0.64 & 0.38 \\
\hline $\mathbf{1}$ & 0.60 & 0.69 & 0.41 \\
\hline $\mathbf{1}$ & 0.53 & 0.72 & 0.38 \\
\hline $\mathbf{1}$ & 0.6 & 0.80 & 0.48 \\
\hline $\mathbf{2 4}$ & 0.68 & 0.58 & 0.39 \\
\hline
\end{tabular}

Table 2. Effect of reaction time on diastereomeric excess, yield and selectivity. $(P=15 \mathrm{MPa}$; $\left.T=42.5^{\circ} \mathrm{C} ; R=12 ; C=3.5 \mathrm{mg} / \mathrm{ml}\right)$

Above an equilibration time of $0.5 \mathrm{~h}$, de and $S$ values do not exhibit any clear trends. Although varying the equilibration time does not change the separation efficiency, a minimal equilibration time is required. As both diastereomeric excess and selectivity values are higher in equilibrium than at short equilibriation times, thermodynamic control is preferable to achieve better optical resolution. In order to make sure that equilibrium is reached, one hour of reaction time is recommended.

\subsection{The apparent concentration of the diastereomeric salt}

The concentration of the precipitate has a known effect on the yields of an antisolvent precipitation [48], but this effect was not investigated for an optical resolution so far. In case of an antisolvent precipitation, the goal is to completely solidify the solute at a certain particle size and morphology. By contrast, optical resolution is only possible when part of the solute remains dissolved. The amount of diastereomeric salt used to prepare the organic solution was set by changing the amount of racemic ibuprofen and $(S)$-phenylglycinol while the amount of methanol was kept constant. 


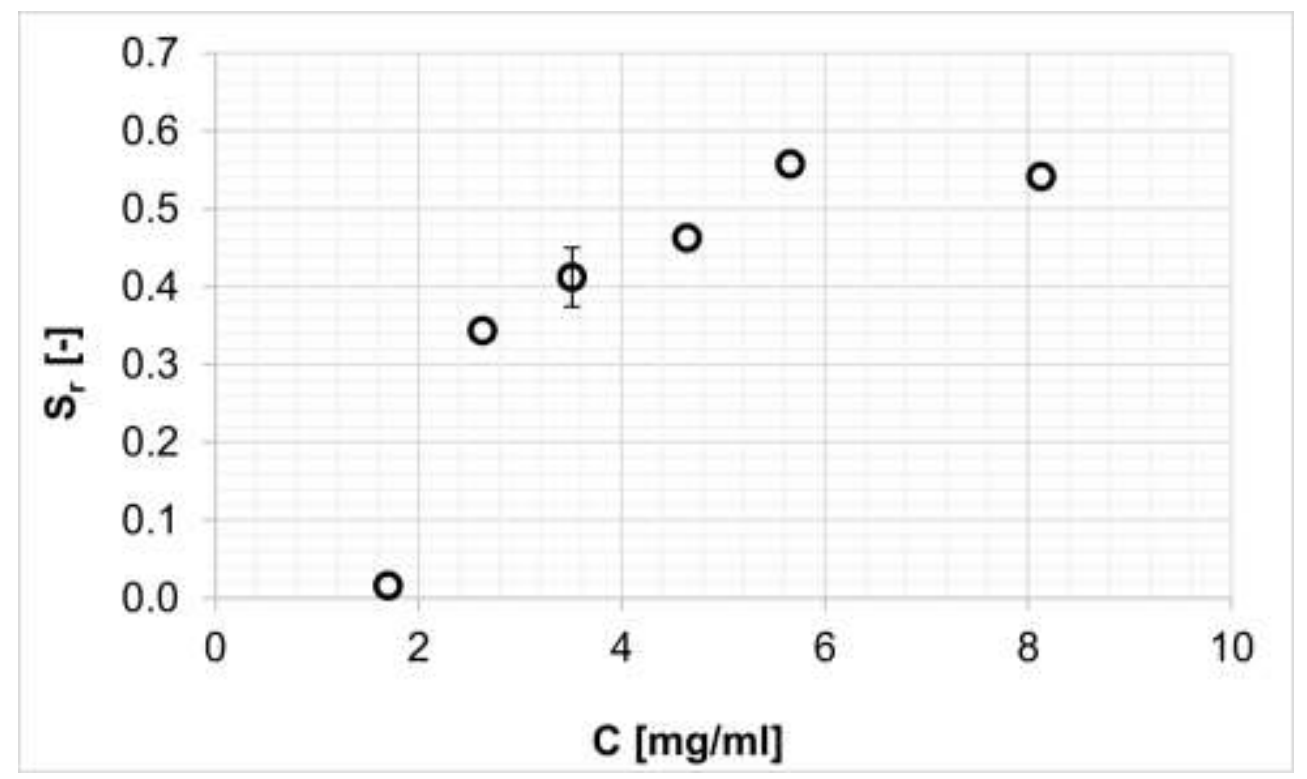

Fig. 2. Effect of the apparent concentration of the diastereomeric salt $(P=15 \mathrm{MPa} ; \mathrm{T}=$ $42.5^{\circ} \mathrm{C} ; R=12 ; t=1 \mathrm{~h}$ ). Standard deviation was 0.038 , calculated using 5 repeated measurements at $C=3.5 \mathrm{mg} / \mathrm{ml}$.

Figure 2. shows the selectivity of the raffinate against the apparent concentration of the diastereomeric salt in the reactor. The selectivity increases slightly above diastereomeric salt concentrations of $2.6 \mathrm{mg} / \mathrm{ml}$, caused by the slight increase in the raffinate yield, while de was constant $(\sim 0.6)$. The slight increase in the selectivity is caused by increasing yield with increasing $C$.

The mass of the precipitated salt is determined either by the apparent solubility of the salt, or as reported in previous papers [32][46], by the dissociation of the salts. Figure 3. shows the raffinate mass against the theoretical salt mass. 


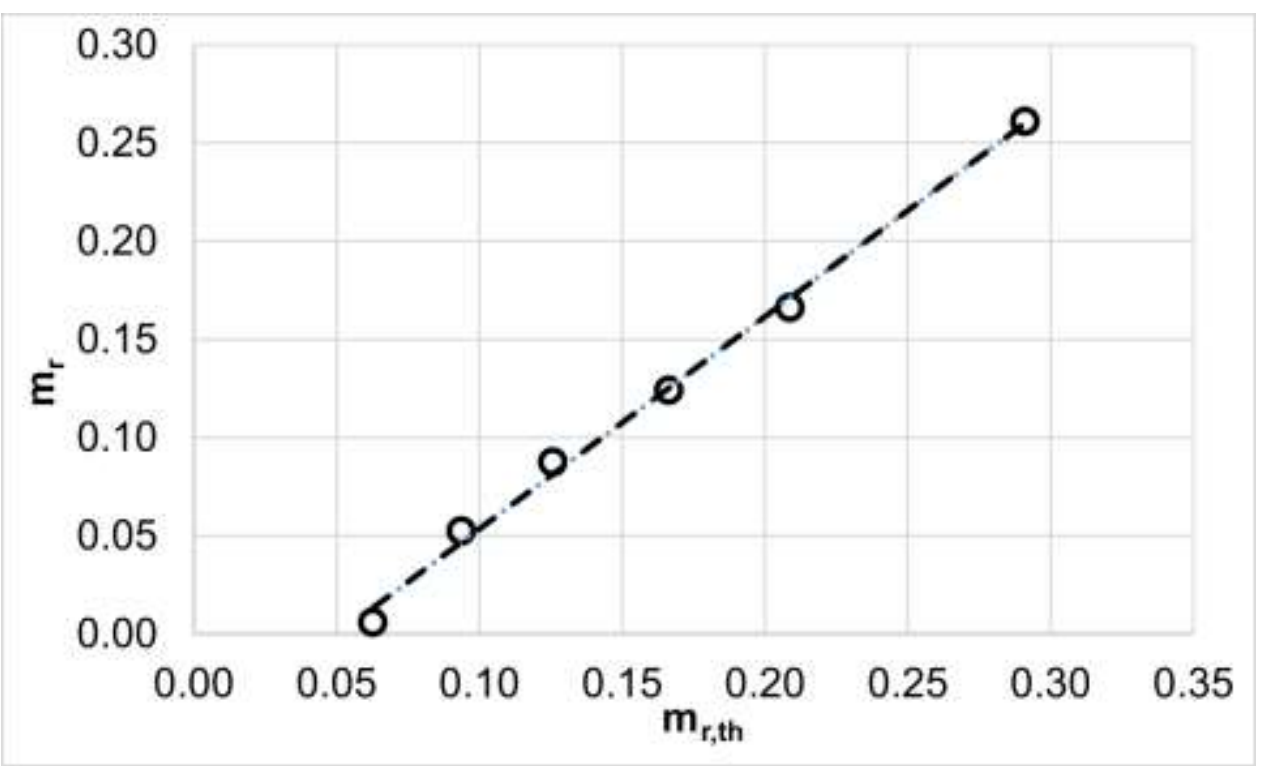

Fig. 3. Effect of the theoretical mass of salt $\left(P=15 \mathrm{MPa} ; \mathrm{T}=42.5^{\circ} \mathrm{C} ; \mathrm{R}=12 ; t=1 \mathrm{~h}\right)$. Dashed line indicates fitted linear equation: $m_{r}=1.081 m_{r, t h}-0.0546, R^{2}=0.9962$.

Based on the excellent linear fitting, it can be concluded that during each experiment, 0.0546 $\mathrm{g}$ of diastereomeric salt is dissolved in the fluid phase and is therefore extracted. The mass corresponds to $1.4 \mathrm{mg} / \mathrm{ml}$ apparent solubility of the diastereomeric salts at the given conditions.

It is recommended to start the process with a solution nearly saturated with the diastereomeric salt (based on the atmospheric solubility of the salt).

\subsection{Carbon dioxide-methanol molar ratio}

The concentration of the organic solvent is one of the most important parameters of an antisolvent precipitation or fractionation. However, the effect is typically highly non-linear [36], as we also found in our current investigation (Figure 4.). During each measurement, the apparent salt concentration was constant $(3.5 \mathrm{mg} / \mathrm{ml})$ and the amount of methanol was varied. The upper limit was determined by the atmospheric solubility of the diastereomeric salts in methanol. 


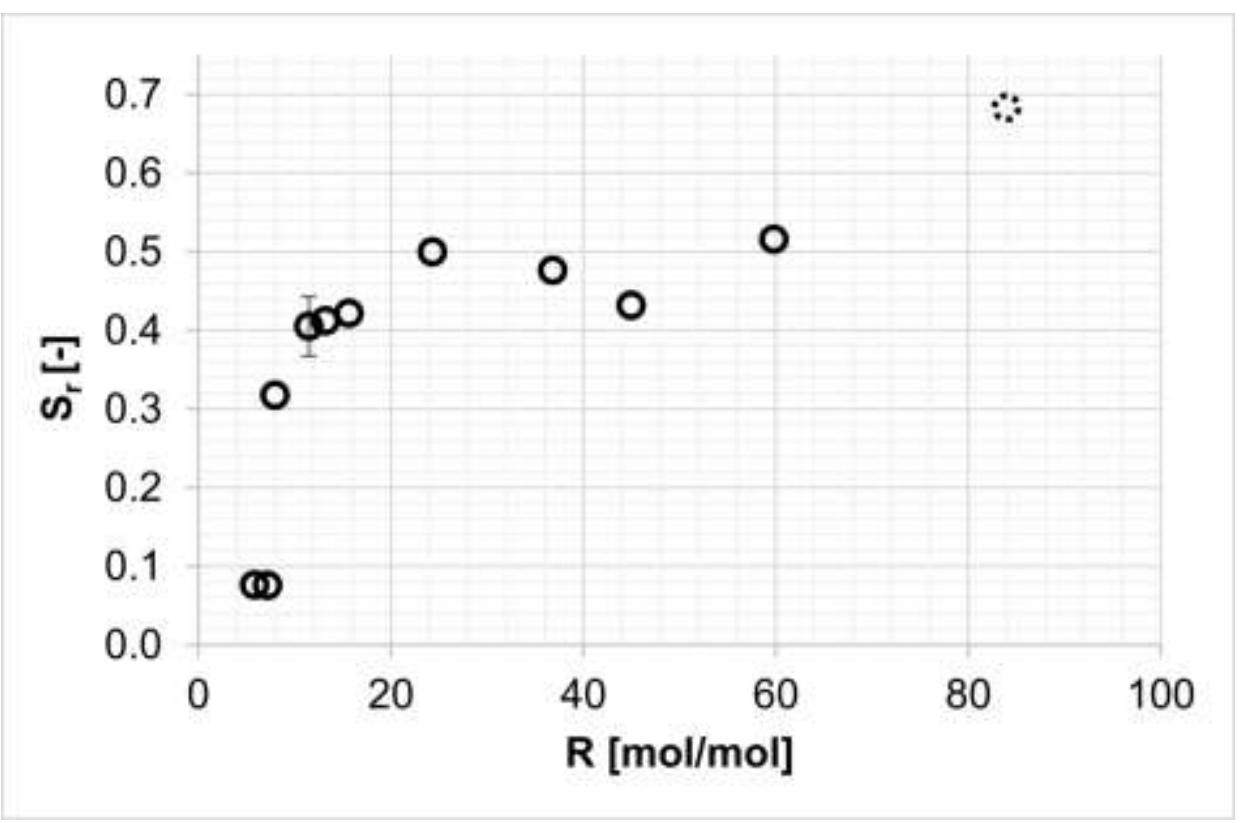

Fig. 4. Effects of carbon dioxide-methanol molar ratio on the selectivity. $(P=15 \mathrm{MPa} ; \mathrm{T}=$ $42.5^{\circ} \mathrm{C} ; t=1 \mathrm{~h} ; \mathrm{C}=3.5 \mathrm{mg} / \mathrm{ml}$ ) Deviation was 0.038 , calculated using 5 repeated measurements at $R=11.5$.

When $R>11$, selectivity, diastereomeric purity and raffinate yield are all approximately constant. The selectivity sharply decreases when $R$ goes below 11 due to the increased solvent power of the solvent mixture. The more polar solvent mixture dissolved the majority of the diastereomeric salt resulting in low yields. This also means that the minimal applicable values of $C$ (see 3.3) and $R$ are not independent.

The selectivity value at $\mathrm{R}=83$ is a clear outlier. This exceptional phenomenon occurs because the solution was already saturated at the beginning of the experiment, likely leading to the inoculation starting at much lower carbon dioxide pressures compared to other experiments.

\subsection{Pressure and temperature}

The effects of pressure and temperature were studied by a 3-level 2-factor experimental design, where the levels of pressure and temperature were $10-15-20 \mathrm{MPa}$ and $35-42.5-50^{\circ} \mathrm{C}$, respectively. Three repetitions were performed at the center of the experimental design. The results are shown in Table 3.

\begin{tabular}{|c|c|c|c|c|c|}
\hline $\mathbf{P}[\mathbf{M P a}]$ & $\mathbf{T}\left[{ }^{\circ} \mathbf{C}\right]$ & $\mathbf{R}[-]$ & $\mathbf{d e}$ & $\mathbf{Y}_{\mathbf{r}}$ & $\mathbf{S}_{\mathbf{r}}$ \\
\hline 10 & 35 & 12.2 & 0.59 & 0.76 & 0.45 \\
\hline 10 & 42.5 & 10.4 & 0.58 & 0.81 & 0.47 \\
\hline
\end{tabular}




\begin{tabular}{|c|c|c|c|c|c|}
\hline 10 & 50 & 8.7 & 0.37 & 0.98 & 0.36 \\
\hline 15 & 35 & 13.7 & 0.54 & 0.70 & 0.38 \\
\hline 15 & 42.5 & 13.2 & 0.60 & 0.69 & 0.41 \\
\hline 15 & 42.5 & 11.5 & 0.68 & 0.64 & 0.43 \\
\hline 15 & 42.5 & 11.5 & 0.64 & 0.63 & 0.41 \\
\hline 15 & 50 & 11.3 & 0.58 & 0.80 & 0.46 \\
\hline 20 & 35 & 14.1 & 0.60 & 0.57 & 0.34 \\
\hline 20 & 42.5 & 15.7 & 0.63 & 0.73 & 0.46 \\
\hline 20 & 50 & 13.6 & 0.63 & 0.51 & 0.32 \\
\hline
\end{tabular}

Table 3. Effect of pressure and temperature on diastereomeric excess, yield and selectivity. ( $t=1 \mathrm{~h} ; \mathrm{C}=3.5 \mathrm{mg} / \mathrm{ml}, 5.4$ (V/V\%) methanol in the reactor)

The results were evaluated using Statistica 13.1 . The data point at $10 \mathrm{MPa}$ and $50^{\circ} \mathrm{C}$ (dark grey background in Table 3.) is an outlier, with a diastereomeric purity of 0.37 and a very high yield (0.98). Visual observation of the carbon dioxide-methanol-diastereomeric salt system in a view cell unit confirmed that at $10 \mathrm{MPa}$ and $50^{\circ} \mathrm{C}, 3$ phases are formed, contrary to results reported in the literature [49]. The presence of the salt probably changes the phase relations.

The presence of one solid, one liquid and one fluid phase is the reason of the decreased efficiency of the extraction step. Due to this critical mixing phenomenon [35], the results could not be evaluated statistically as an experimental design.

The effect of pressure is minimal, the selectivity of the raffinate increasing slightly as the pressure decreases. This is because the components are more soluble at higher pressures, thus slightly more diastereomeric salt can be extracted. Diastereomeric purity values are around 0.6 , so the selectivity, being a product of the diastereomeric purity and the raffinate yield reduces the effect of pressure. Temperature does not have a significant effect either, no trend can be identified.

It can be stated that lower pressures is slightly more favorable and also more economical, while lower temperatures at a given pressure are also favourable, thus $35^{\circ} \mathrm{C}$ and $10 \mathrm{MPa}$ can be suggested as the operational temperature and pressure, respectively.

\subsection{XRD and SEM analysis}

After each experiment, raffinate XRD diffractograms and SEM images were recorded. The obtained crystal forms were the same in each raffinate sample, as indicated by the peak 
positions and relative intensities in the diffractograms. XRD patterns of the reactants differ from the patterns of the raffinate and from the pattern of the $(S)-\mathrm{IBU}-(S)-\mathrm{PhG}$ salt as well (Fig. 5.). The $(S)$-IBU-(S)-PhG salt reference XRD pattern was obtained by dissolving molar equivalent amounts of the reactants in methanol and evaporating the solvent in vacuum.

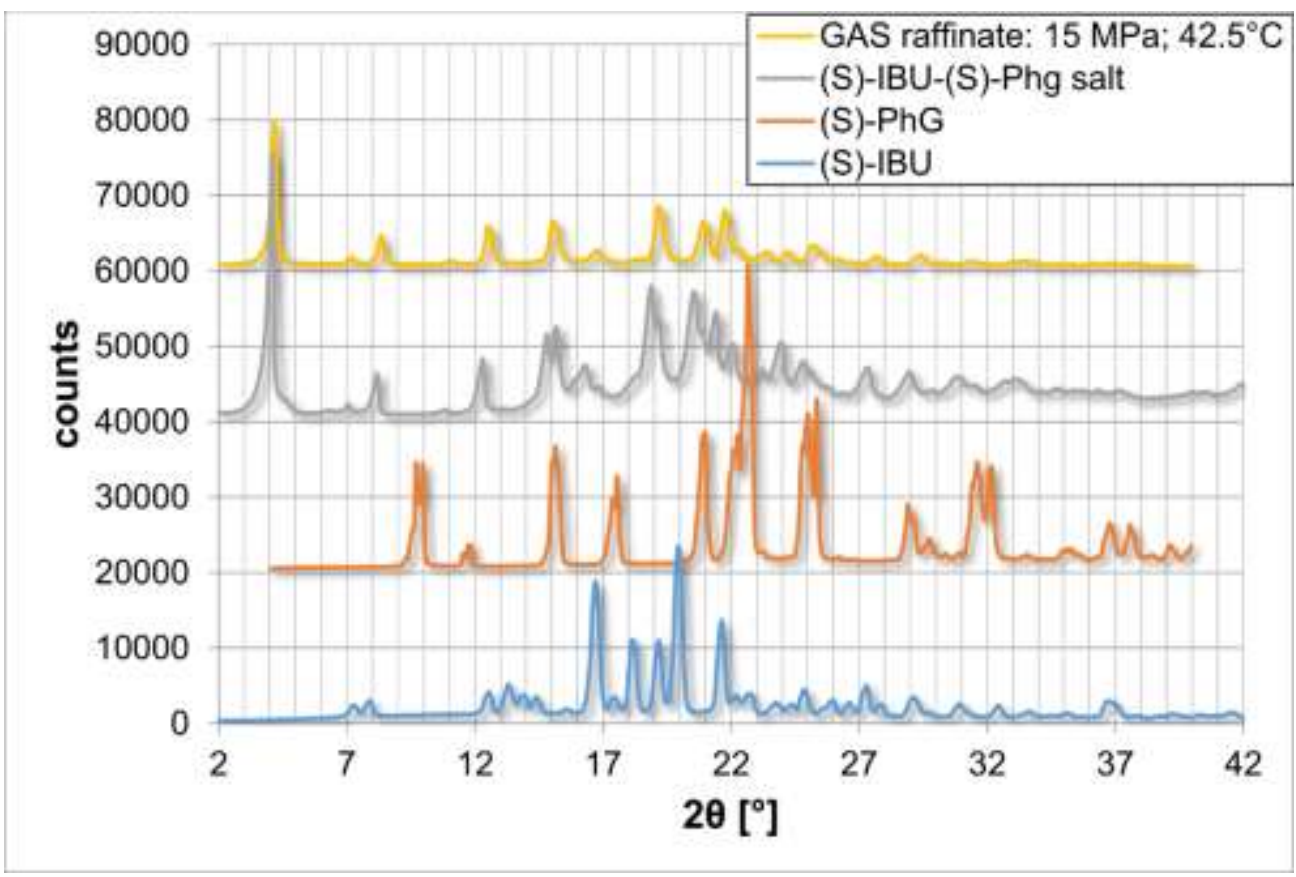

Fig 5. Diffractogram of GAS raffinate, raw materials (ibuprofen and (S)-2-phenylglycinol) and atmospheric reference. GAS raffinate obtained from methanol. $\left(P=15 \mathrm{MPa} ; \mathrm{T}=42.5^{\circ} \mathrm{C}\right.$; $R=12 ; t=1 \mathrm{~h} ; C=3.5 \mathrm{mg} / \mathrm{ml})$

The morphology and crystal habits of the raffinates were the same in all experiments: long fibrous crystals were observed (Fig. 6.) with lengths of up to hundreds of micrometers and diameters between 400-800 $\mathrm{nm}$.

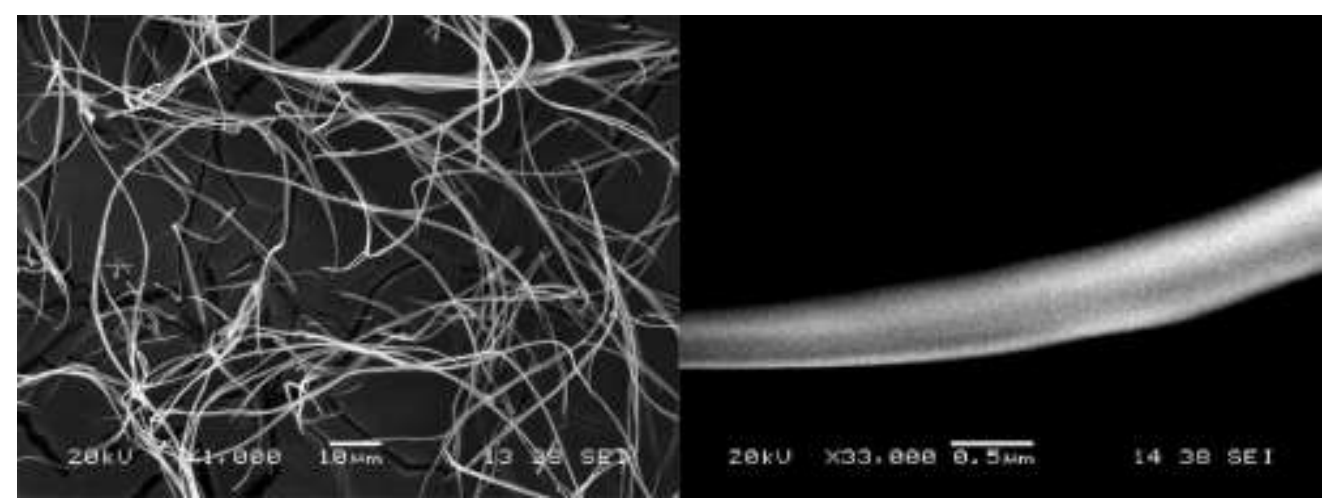

Fig 6. SEM images of GAS raffinates obtained from $\mathrm{MeOH}\left(P=15 \mathrm{MPa} ; \mathrm{T}=42.5^{\circ} \mathrm{C} ; \mathrm{R}=12\right.$; $t=1 \mathrm{~h} ; \mathrm{C}=3.5 \mathrm{mg} / \mathrm{ml}$ ) 


\subsection{Diastereomeric enrichment by repeated resolution}

In a single optical resolution step, the maximal diastereomeric excess value was $70 \%$, while at optimal conditions (maximal selectivity) the value of $d e$ was appr. 60\%. Consequently, purification of the scalemic mixtures is required to achieve high de values. The purification was investigated experimentally at the optimal operational parameter values determined in the previous sections by repeated resolutions. Figure 7. presents the experimental data in the form of a general purification diagram suggested by Faigl et al [45]. The purification is not limited in the investigated range by any non-ideal behaviour.

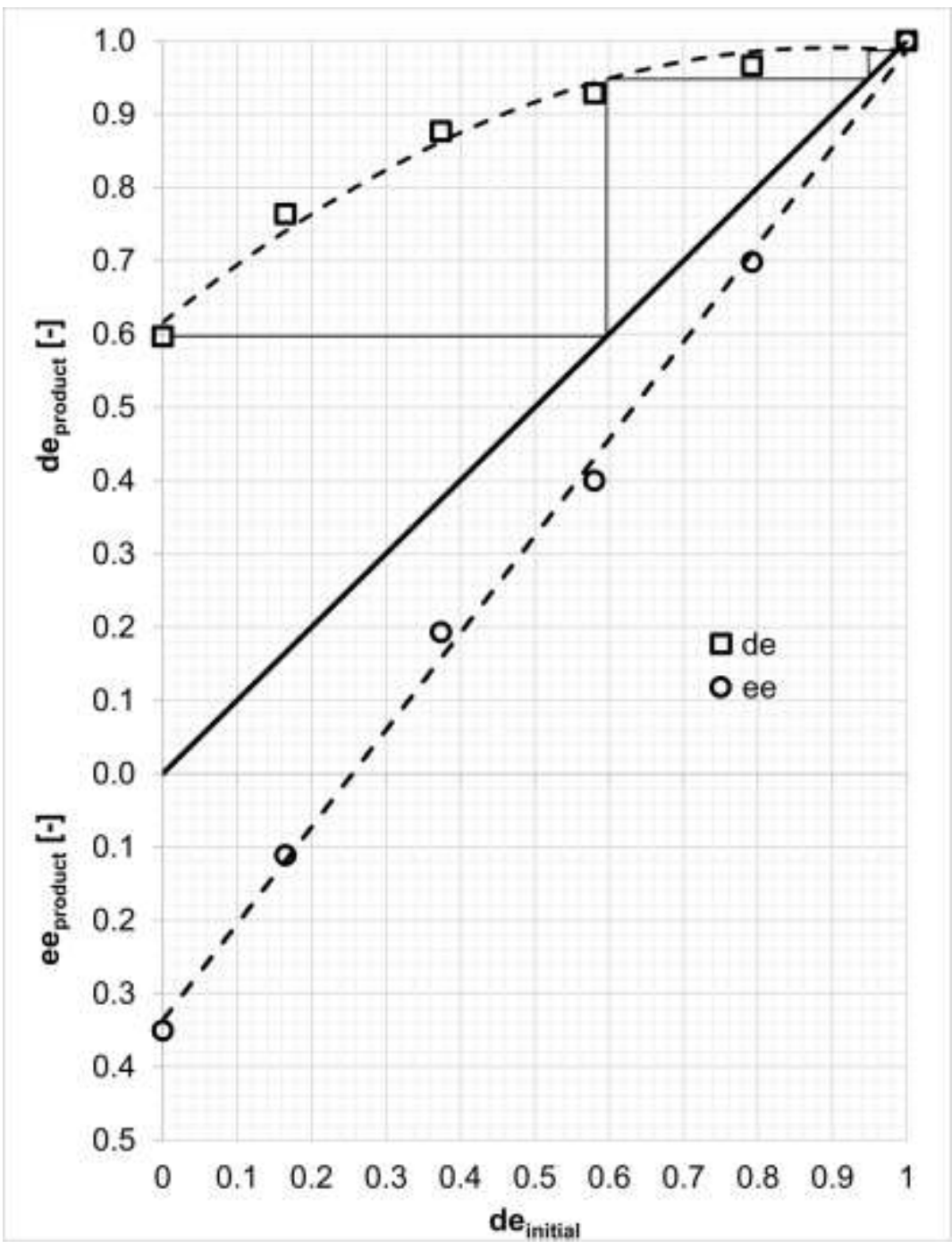

Fig. 7. Enantiomeric enrichment of ibuprofen with $(S)$-phenylglycinol via half molar equivalent resolution by GAS method ( $P=15 \mathrm{MPa} ; \mathrm{T}=42.5^{\circ} \mathrm{C} ; R=12 ; t=1 \mathrm{~h} ; \mathrm{C}=3.5 \mathrm{mg} / \mathrm{ml}$ ). Solid black line indicates initial diastereomeric excess equal to the optical purity of the product. Dashed lines only indicate general trends to guide the eye. Purification steps indicated by thin black lines are theoretical only, no measurements were carried out. 
In three consecutive steps, 0.99 de can be achieved (see Figure 7.) with relatively high raffinate yields $\left(\mathrm{Y}_{\mathrm{r}}=0.7-0.9\right)$. In the raffinate, higher further purification can be achieved than in the extract, even at higher initial purities.

\section{Conclusions}

A novel optical resolution method for ibuprofen with optically active phenylglycinol was investigated. Gas antisolvent fractionation with carbon dioxide is a fast and suitable method for the diastereomeric salt based optical resolution, as well as for diastereomeric enrichment. Compared to the published optimised optical resolution of ibuprofen resulting in 0.43 [50], 0.42 [15], 0.44 [36], the novel method afforded selectivities as high as 0.55.

The effects of operational parameters were analyzed and optimized. The optical resolution system is very stable in the sense that above (or below) the critical values of each operational parameter, diastereomeric excess and selectivity values varied only slightly. By contrast, in other ranges, each parameter caused a sharp drop in resolution efficiency. Antisolvent precipitation and optical resolution are both complex methods requiring a deep understanding of high pressure phase equilibria, processing and chiral chemistry as well. This detailed study could aid researchers planning to develop a novel optical resolution with antisolvent precipitation in identifying the most influential parameters.

The structure of the crystals formed is identical to the structure of the reference crystals made at atmospheric pressure. Crystal habits are similar according to SEM images: thin, fibrous structure, with diameters between 400-800 nm, corresponding to previous results [36].

Enantiomeric enrichment of scalemic ibuprofen mixtures was successfully achieved by repeated resolution at the optimal operational parameters. No unusual behaviours were found and diastereomeric excess values of $>99 \%$ can be achieved in three consecutive steps with overall yields of 0.71 .

\section{Acknowledgements}

This work is related to the National Research, Development and Innovation Fund of Hungary in the frame of FIEK_16-1-2016-0007 (Higher Education and Industrial Cooperation Center), K108979, PD-109129 projects. We highly appreciate the linguistic suggestions of Dr. György Bánsághi. 


\section{Symbols used}

\section{Materials}

$\mathrm{CO}_{2}$

carbon dioxide

Methods

\section{GAS}

$\mathrm{CE}$

XRD

SEM

\section{Quantities}

n [mol]

$\mathrm{m}[\mathrm{g}]$

$\mathrm{M}[\mathrm{g} / \mathrm{mol}]$

$\mathrm{R}$ [mol/mol]

C $[\mathrm{mg} / \mathrm{ml}]$

$\mathrm{t}[\mathrm{h}]$

$\mathrm{T}\left[{ }^{\circ} \mathrm{C}\right]$

$\mathrm{P}[\mathrm{MPa}]$

Y [-]

$e e[-]$

de [-]

$\mathrm{S}[-]$

$\mathrm{V}[\mathrm{ml}]$

\section{Indices}

r

th

initial

product gas antisolvent

capillary electrophoresis

powder X-ray diffraction

Scanning Electron Microscope

molar quantity

mass

molecular weight

carbon dioxide-methanol molar ratio

diastereomeric salt concentration relative to the reactor volume

reaction time

experiment temperature

experiment pressure

yield

enantiomeric excess

diastereomeric excess

selectivity

reactor volume

raffinate

theoretical

initial optical purity

product optical purity 


\section{References}

[1] H. Murakami, From racemates to single enantiomers - Chiral synthetic drugs over the last 20 years, Top. Curr. Chem. 269 (2006) 273-299. doi:10.1007/128_2006_072.

[2] S. Mascia, P.L. Heider, H. Zhang, R. Lakerveld, B. Benyahia, P.I. Barton, R.D. Braatz, C.L. Cooney, J.M.B. Evans, T.F. Jamison, K.F. Jensen, A.S. Myerson, B.L. Trout, End-to-end continuous manufacturing of pharmaceuticals: Integrated synthesis, purification, and final dosage formation, Angew. Chemie - Int. Ed. 52 (2013) 1235912363. doi:10.1002/anie.201305429.

[3] E.J. Beckman, Supercritical and near-critical CO2 in green chemical synthesis and processing, J. Supercrit. Fluids. 28 (2004) 121-191. doi:10.1016/S08968446(03)00029-9.

[4] E. Rója, M. Gagoś, A. Dobrzyńska-Inger, Cost Optimization of Extract Production in Supercritical Extraction Process with the Use of CO2 - A Novel Approach, Procedia Eng. 42 (2012) 323-328. doi:10.1016/j.proeng.2012.07.423.

[5] A.W. Kjellow, O. Henriksen, Supercritical wood impregnation, J. Supercrit. Fluids. 50 (2009) 297-304. doi:10.1016/j.supflu.2009.06.013.

[6] J. Fernandes, A.W. Kjellow, O. Henriksen, Modeling and optimization of the supercritical wood impregnation process-Focus on pressure and temperature, J. Supercrit. Fluids. 66 (2012) 307-314. doi:10.1016/J.SUPFLU.2012.03.003.

[7] D. Varga, S. Alkin, P. Gluschitz, B. Péter-Szabó, E. Székely, T. Gamse, Supercritical fluid dyeing of polycarbonate in carbon dioxide, J. Supercrit. Fluids. 116 (2016) 111116. doi:10.1016/J.SUPFLU.2016.05.018.

[8] M. Champeau, J.-M. Thomassin, T. Tassaing, C. Jérôme, Drug loading of polymer implants by supercritical CO2 assisted impregnation: A review, J. Control. Release. 209 (2015) 248-259. doi:10.1016/J.JCONREL.2015.05.002.

[9] W. Leitner, Supercritical carbon dioxide as a green reaction medium for catalysis, Acc. Chem. Res. 35 (2002) 746-756. doi:10.1021/ar010070q.

[10] Ž. Knez, M. Habulin, V. Krmelj, Enzyme catalyzed reactions in dense gases, J. Supercrit. Fluids. 14 (1998) 17-29. doi:10.1016/S0896-8446(98)00097-7.

[11] E. Fogassy, M. Ács, T. Szili, B. Simándi, J. Sawinsky, Molecular chiral recognition in supercritical solvents, Tetrahedron Lett. 35 (1994) 257-260. doi:10.1016/S00404039(00)76525-7.

[12] S. Keszei, B. Simándi, E. Székely, E. Fogassy, S. Kemény, Supercritical fluid 
extraction: a novel method for the resolution of tetramisole, Tetrahedron: Asymmetry. 10 (1999) 1275-1281. doi:10.1016/S0957-4166(99)00109-3.

[13] E. Székely, B. Simándi, R. Illés, P. Molnár, I. Gebefügi, I. Kmecz, E. Fogassy, Application of supercritical fluid extraction for fractionation of enantiomers, J. Supercrit. Fluids. 31 (2004) 33-40. doi:10.1016/j.supflu.2003.09.016.

[14] B. Simándi, S. Keszei, E. Fogassy, S. Kemény, J. Sawinsky, Separation of enantiomers by supercritical fluid extraction, J. Supercrit. Fluids. 13 (1998) 331-336. doi:10.1016/S0896-8446(98)00068-0.

[15] G. Bánsághi, E. Székely, D.M. Sevillano, Z. Juvancz, B. Simándi, Diastereomer salt formation of ibuprofen in supercritical carbon dioxide, J. Supercrit. Fluids. 69 (2012) 113-116. doi:10.1016/j.supflu.2012.05.016.

[16] I. Khanna, Drug discovery in pharmaceutical industry: productivity challenges and trends, Drug Discov. Today. 17 (2012) 1088-1102. doi:10.1016/J.DRUDIS.2012.05.007.

[17] P.M. Gallagher, M.P. Coffey, V.J. Krukonis, W.W. Hillstrom, Gas anti-solvent recrystallization of RDX: Formation of ultra-fine particles of a difficult-to-comminute explosive, J. Supercrit. Fluids. 5 (1992) 130-142. doi:10.1016/0896-8446(92)90030-N.

[18] V. Martín, R. Romero-Díez, S. Rodríguez-Rojo, M.J. Cocero, Titanium dioxide nanoparticle coating in fluidized bed via supercritical anti-solvent process (SAS), Chem. Eng. J. 279 (2015) 425-432. doi:10.1016/J.CEJ.2015.05.014.

[19] N. Esfandiari, Production of micro and nano particles of pharmaceutical by supercritical carbon dioxide, J. Supercrit. Fluids. 100 (2015) 129-141. doi:10.1016/J.SUPFLU.2014.12.028.

[20] E. Reverchon, R. Adami, Nanomaterials and supercritical fluids, J. Supercrit. Fluids. 37 (2006) 1-22. doi:10.1016/j.supflu.2005.08.003.

[21] C. Roy, D. Vrel, A. Vega-González, P. Jestin, S. Laugier, P. Subra-Paternault, Effect of $\mathrm{CO} 2$-antisolvent techniques on size distribution and crystal lattice of theophylline, J. Supercrit. Fluids. 57 (2011) 267-277. doi:10.1016/j.supflu.2011.03.002.

[22] M. Rossmann, A. Braeuer, A. Leipertz, E. Schluecker, Manipulating the size, the morphology and the polymorphism of acetaminophen using supercritical antisolvent (SAS) precipitation, J. Supercrit. Fluids. 82 (2013) 230-237. doi:10.1016/j.supflu.2013.07.015.

[23] C. Neurohr, A. Erriguible, S. Laugier, P. Subra-Paternault, Challenge of the supercritical antisolvent technique SAS to prepare cocrystal-pure powders of naproxen- 
nicotinamide, Chem. Eng. J. 303 (2016) 238-251. doi:10.1016/j.cej.2016.05.129.

[24] J. Jung, M. Perrut, Particle design using supercritical fluids: Literature and patent survey, J. Supercrit. Fluids. 20 (2001) 179-219. doi:10.1016/S0896-8446(01)00064-X.

[25] P.G. Debenedetti, J.W. Tom, Y. Sang-Do, L. Gio-Bin, Application of supercritical fluids for the production of sustained delivery devices, J. Control. Release. 24 (1993) 27-44. doi:10.1016/0168-3659(93)90166-3.

[26] E. Reverchon, I. De Marco, Mechanisms controlling supercritical antisolvent precipitate morphology, Chem. Eng. J. 169 (2011) 358-370. doi:10.1016/j.cej.2011.02.064.

[27] Ž. Knez, M. Knez Hrnčič, M. Škerget, Particle Formation and Product Formulation Using Supercritical Fluids, Annu. Rev. Chem. Biomol. Eng. 6 (2015) 379-407. doi:10.1146/annurev-chembioeng-061114-123317.

[28] J.L. Marqués, G. Della Porta, E. Reverchon, J.A.R. Renuncio, A.M. Mainar, Supercritical antisolvent extraction of antioxidants from grape seeds after vinification, J. Supercrit. Fluids. 82 (2013) 238-243. doi:10.1016/J.SUPFLU.2013.07.005.

[29] A.P. Sánchez-Camargo, J.A. Mendiola, A. Valdés, M. Castro-Puyana, V. GarcíaCañas, A. Cifuentes, M. Herrero, E. Ibáñez, Supercritical antisolvent fractionation of rosemary extracts obtained by pressurized liquid extraction to enhance their antiproliferative activity, J. Supercrit. Fluids. 107 (2016) 581-589. doi:10.1016/J.SUPFLU.2015.07.019.

[30] A. Martín, M.J. Cocero, Separation of enantiomers by diastereomeric salt formation and precipitation in supercritical carbon dioxide. Application to the resolution of mandelic acid, J. Supercrit. Fluids. 40 (2007) 67-73. doi:10.1016/j.supflu.2006.03.018.

[31] A. Kordikowski, P. York, D. Latham, Resolution of ephedrine in supercritical CO2: A novel technique for the separation of chiral drugs, J. Pharm. Sci. 88 (1999) 786-791. doi:10.1021/js980459f.

[32] G. Bánsághi, L. Lőrincz, I.M. Szilágyi, J. Madarász, E. Székely, Crystallization and Resolution of cis-Permethric Acid with Carbon Dioxide Antisolvent, Chem. Eng. Technol. 37 (2014) 1417-1421. doi:10.1002/ceat.201300718.

[33] A. Zodge, M. Körösi, M. Tárkányi, J. Madarász, I.M. Szilágyi, T. Sohajda, E. Székely, Gas Antisolvent Approach for the Precipitation of $\alpha$-Methoxyphenylacetic Acid - (R)1-Cyclohexylethylamine Diateromeric Salt, Chem. Biochem. Eng. Q. 31 (2017) 335341. doi:10.15255/CABEQ.2016.1023.

[34] M. Körösi, J. Madarász, T. Sohajda, E. Székely, Fast further purification of 19

(C) $<2018>$. This manuscript version is made available under the CC-BY-NC-ND 4.0 license http://creativecommons.org/licenses/by-nc-nd/4.0/ 
diastereomeric salts of a nonracemic acid by gas antisolvent fractionation, Chirality. 29 (2017) 610-615. doi:10.1002/chir.22730.

[35] M. Körösi, A. Sedon, K. Komka, T. Sohajda, E. Székely, Gas Antisolvent Fractionation : a New Method to Obtain Enantiopure Compounds, a Case Study on Mandelic Acid, Period. Polytech. Chem. Eng. (2018). doi:10.3311/PPch.11741.

[36] L. Lőrincz, G. Bánsághi, M. Zsemberi, S. de Simón Brezmes, I.M. Szilágyi, J. Madarász, T. Sohajda, E. Székely, Diastereomeric salt precipitation based resolution of ibuprofen by gas antisolvent method, J. Supercrit. Fluids. 118 (2016) 48-53. doi:10.1016/j.supflu.2016.07.021.

[37] M. Körösi, J. Madarász, T. Sohajda, E. Székely, A fast, new method to enhance the enantiomeric purity of non-racemic mixtures: self-disproportionation of enantiomers in the gas antisolvent fractionation of chlorine-substituted mandelic acid derivatives, Tetrahedron: Asymmetry. 28 (2017) 1568-1572. doi:10.1016/J.TETASY.2017.09.005.

[38] S.S. Adams, P. Bresloff, G.C. Mason, Pharmacological difference between the optical isomers of ibuprofen: evidence for metabolic inversion of the (-)-isomer, J. Pharm. Pharmacol. 28 (1976) 156-157.

[39] T. Manimaran, G.P. Stahly, Optical purification of profen drugs, Tetrahedron: Asymmetry. 4 (1993) 1949-1954. doi:10.1016/S0957-4166(00)80436-X.

[40] T. Manimaran, F.J. Impastato, U.S. patent 5015764, 1991. doi:10.1074/JBC.274.42.30033.(51).

[41] H.-H. Tung, S. Waterson, S.D. Reynolds, Formation and resolution of ibuprofen lysinate, 1991. http://www.google.com/patents/US4994604.

[42] R. Valentine, Enantiomeric Resolution of Racemic Ibuprofen in Supercritical Carbon Dioxide Using a Chiral Resolving Agent, University of Pittsburgh, 2002. http://dscholarship.pitt.edu/id/eprint/6600.

[43] F. Faigl, E. Fogassy, M. Nógrádi, E. Pálovics, J. Schindler, Strategies in optical resolution: a practical guide, Tetrahedron: Asymmetry. 19 (2008) 519-536. doi:10.1016/j.tetasy.2008.02.004.

[44] E.J. Ebbers, B.J.M. Plum, G.J.A. Ariaans, B. Kaptein, Q.B. Broxterman, A. Bruggink, B. Zwanenburg, New resolving bases for ibuprofen and mandelic acid: qualification by binary phase diagrams, Tetrahedron: Asymmetry. 8 (1997) 4047-4057. doi:10.1016/S0957-4166(97)00557-0.

[45] F. Faigl, E. Fogassy, M. Nógrádi, E. Pálovics, J. Schindler, Separation of non-racemic mixtures of enantiomers: an essential part of optical resolution., Org. Biomol. Chem. 8 
(2010) 947-959. doi:10.1039/b917564d.

[46] L. Lőrincz, M. Zsemberi, G. Bánsághi, T. Sohajda, E. Székely, Towards

Diastereomeric Pure Salts with Antisolvent Methods, Chem. Eng. Technol. (2018). doi:10.1002/ceat.201700429.

[47] E. Fogassy, A. Lopata, F. Faigl, F. Darvas, M. Ács, L. Tõke, A quantitative approach to optical resolution, Tetrahedron Lett. 21 (1980) 647-650. doi:10.1016/S00404039(01)85582-9.

[48] E. Reverchon, I. De Marco, E. Torino, Nanoparticles production by supercritical antisolvent precipitation: A general interpretation, J. Supercrit. Fluids. 43 (2007) 126138. doi:10.1016/j.supflu.2007.04.013.

[49] L. Gil, S.T. Blanco, C. Rivas, E. Laga, J. Fernández, M. Artal, I. Velasco, Experimental determination of the critical loci for $\{\mathrm{n}-\mathrm{C} 6 \mathrm{H} 14$ or $\mathrm{CO} 2+$ alkan-1-ol $\}$ mixtures.

Evaluation of their critical and subcritical behavior using PC-SAFT EoS, J. Supercrit. Fluids. 71 (2012) 26-44. doi:10.1016/j.supflu.2012.07.008.

[50] P. Molnár, E. Székely, B. Simándi, S. Keszei, J. Lovász, E. Fogassy, Enantioseparation of ibuprofen by supercritical fluid extraction, J. Supercrit. Fluids. 37 (2006) 384-389. doi:10.1016/j.supflu.2005.10.009. 